\title{
CPT-BASED LIQUEFACTION ASSESSMENT BY USING FUZZY-NEURAL NETWORK
}

\author{
Shuh-Gi Chern \\ Department of Habor and River Engineering, National Taiwan Ocean University, Keelung, Taiwan, R.O.C., \\ sgchern@ntou.edu.tw \\ Ching-Yinn Lee \\ Department of Habor and River Engineering, National Taiwan Ocean University, Keelung, Taiwan, R.O.C. \\ Chin-Chen Wang \\ Department of Habor and River Engineering, National Taiwan Ocean University, Keelung, Taiwan, R.O.C.
}

Follow this and additional works at: https://jmstt.ntou.edu.tw/journal

Part of the Civil and Environmental Engineering Commons

\section{Recommended Citation}

Chern, Shuh-Gi; Lee, Ching-Yinn; and Wang, Chin-Chen (2008) "CPT-BASED LIQUEFACTION ASSESSMENT BY USING FUZZY-NEURAL NETWORK," Journal of Marine Science and Technology. Vol. 16: Iss. 2, Article 6.

DOI: $10.51400 / 2709-6998.2024$

Available at: https://jmstt.ntou.edu.tw/journal/vol16/iss2/6

This Research Article is brought to you for free and open access by Journal of Marine Science and Technology. It has been accepted for inclusion in Journal of Marine Science and Technology by an authorized editor of Journal of Marine Science and Technology. 


\title{
CPT-BASED LIQUEFACTION ASSESSMENT BY USING FUZZY-NEURAL NETWORK
}

\author{
Shuh-Gi Chern*, Ching-Yinn Lee*, and Chin-Chen Wang*
}

Key words: fuzzy-neural, network, CPT, liquefaction.

\begin{abstract}
Because of the increasing popularity worldwide of the cone penetration test (CPT) for site characterization, significant progress on the simplified CPT-based methods has been made for evaluation of earthquake induced liquefaction potential of soils. In this study, a fuzzy-neural network combined with 466 CPT field observations is developed to evaluate liquefaction potential of soils. The proposed model combines fuzzy theory with subtractive clustering algorithm to establish a fuzzy-neural system. The study indicates that fuzzy-neural network can successfully describe the complex relationship between seismic parameters, soil parameters, and the liquefaction potential. The fuzzy-neural network model is found to have very good predictive ability and is expected to be very reliable for evaluation of liquefaction potential.
\end{abstract}

\section{INTRODUCTION}

The liquefaction is known as one of the most destructive phenomena caused by earthquake and has been widely seen in loose saturated soil deposit (Niigata, 1964; Alaska, 1964; Tangshan, 1979; Loma Prieta, 1989; Kobe, 1995; Turkey, 1998; Chi-Chi, Taiwan, 1999). In view of serious damages caused by earthquake induced liquefaction, geotechnical engineers are actively engaged in the study of soil liquefaction induced by earthquakes. As of now, they have developed many assessment methods for soil liquefaction. However, it is hard to choose a suitable empirical equation for regression analysis due to the high uncertainty of earthquake environment and soil characteristics. Thus, many scholars and experts attempt to seek analytical models that are more reasonable, simple, easy and accurate than traditional empirical equations for soil liquefaction analysis.

Many of the existing assessment methods were developed from observations of the performance of sites during earthquakes. Previously, geotechnical engineers generally accepted the simple liquefaction analytical model developed by STP-N

Paper submitted 11/10/06; accepted 03/16/07. Author for correspondence: Shuh-Gi Chern (e-mail:sgchern@ntou.edu.tw).

*Department of Habor and River Engineering, National Taiwan Ocean University, Keelung, Taiwan, R.O.C. due to computer speed and analytical ability. In recent years, data processing and analytical ability have greatly increased and CPT has the advantages in being a fast, continuous and accurate measurement of soil parameters. At the same time, the related testing data continued to accumulate, so the potential of applying CPT to liquefaction research has grown significantly. For example, Shibata and Teparaksa [25], Stark and Olsen [26], Olson [21], Robertson and Companella [23], Robertson and Wride [24], and Juang and Chen [11] all adopted CPT-based liquefaction to establish soil liquefaction models and acquired great achievement.

To assess soil liquefaction induced by earthquakes, it is necessary to find the correlation between soil parameters and earthquake factors. However, the relationship between them is highly non-linear. Therefore, an induction cannot be made by pure linear regression or empirical rules. Artificial neural network simulates human thinking and learning and finds corresponding rules with mapping relationship between inputs and outputs for complicated non-linear problems. Many scholars approved that neural network method is a powerful and effective tool and is more accurate and reliable than conventional method to deal with liquefaction problem [3, 10, 12]. However, previous attempts at using neural networks to determine liquefaction potential were inadequate because they can not meet required accuracy without increasing network layers or hidden neurons. Those deficiencies can be addressed by the fuzzy-neural system developed in this study. Subtractive clustering algorithm is used to extract hidden classification rules from data and analyze the system in the study with the divided-and-conquer methodology. Through neural network's learning and reminding ability, 466 collected CPT field observations with a wide range of parameters are incorporated in this fuzzy-neural network to evaluate earthquake induced liquefaction potential.

\section{ELEMENTS OF ANALYSIS}

\section{Fuzzy logic}

The modeling of many systems involve the consideration of some uncertain variables. Besides the statistical uncertainties that handle variables through probability theory, there also exists non-statistical uncertainty that handles variables in a rational framework of "fuzzy set theory". Like human brain that can interpret imprecise and incomplete sensory information, 


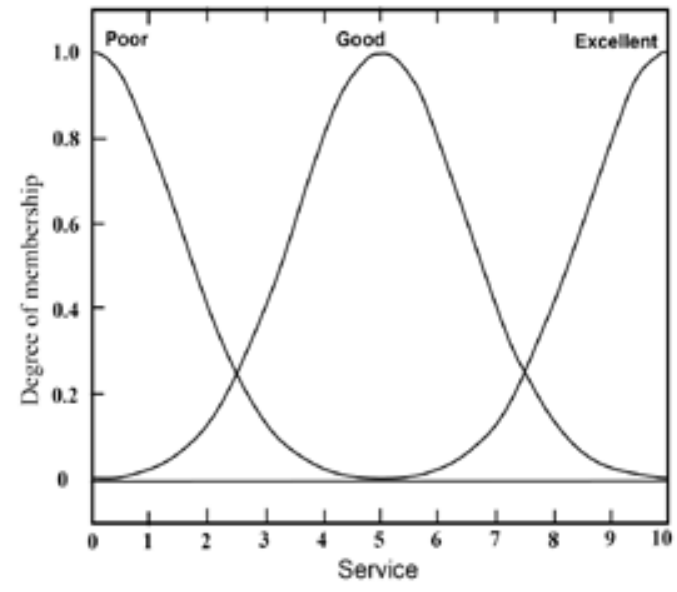

Fig. 1. Illustration of membership function.

"fuzzy logic" provides a systematic and approximate reasoning method to cope with the uncertainties.

In a classic set, the set has a crisp boundary, and the membership value of an object in a class is only 0 or 1 . When the element $x$ belongs to $A$ set, degree of membership $\mu A(x)$ is 1 ; while $x$ does not belong to $A$ set, degree of membership becomes 0 . On the contrary, a fuzzy set is a set without a crisp boundary. The transition from" belong to a set" to "not belong to a set" is gradual, and this transition is characterized by membership functions that give fuzzy sets flexibility in modeling commonly used linguistic expressions, such as poor, good, and excellent, as shown in Fig. 1.

Being a continuous and often ambiguous events, the occurrence of liquefaction may not be appropriate to describe in terms of either/or classification [1]. Instead, liquefaction should be described in terms of degree of liquefaction represented by fuzzy numbers [22]. [22].

A fuzzy variable, " $A$ " is normally expressed as a pair of data

$$
A=\left\{\left(x, \mu_{A}(x)\right) \mid x \in X\right\}
$$

in which $x$ is the element of " $A$ " set; $X$ is a collection of objects denoted by $x$, i.e. $X$ is the universe of discourse; $\mu A(x)$ is called the membership function for the fuzzy set $A$, which defines the degree of an element belonging to a set. The membership function maps $X$ to the membership space $M$, where $M=$ $\{0,1\}$.

Fig. 2 shows the basic framework of fuzzy set that contains several functions, such as fuzzification, fuzzy rule base, fuzzy inference engine and defuzzification. In addition to establishing fuzzy rule base through linguistic fuzzy rules that are transformed from expert knowledge and experience, fuzzy rule base can also be established through special algorithmic rules that obtain inputs and outputs with mathematical calculation. This study adopts subtractive clustering algorithms and obtains normalization to analyze the hidden rules and establishes a fuzzy rule base.

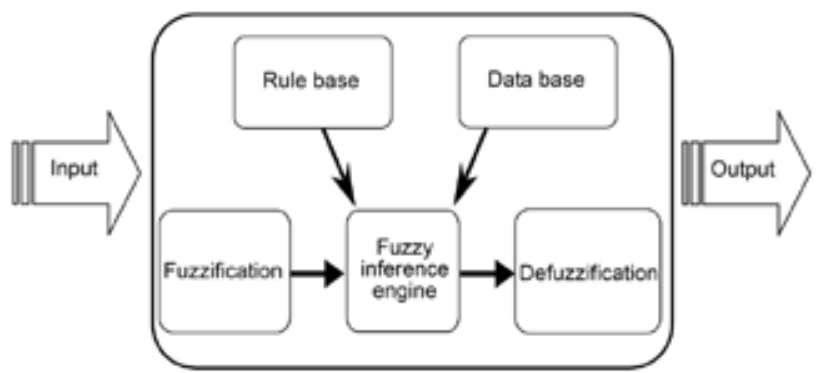

Fig. 2. Basic Frameworks for Fuzzy System.

\section{Subtractive clustering}

Clustering of numerical data forms the basis of many classification and system data from a large data set, producing a concise representation of a system's behavior [9]. Based on the Mountain Method that was developed by Yager et al. [32], Chiu [9] proposed subtractive clustering that considers each data point as a potential cluster center and a measure of the potential of data point xi is define as:

$$
\begin{gathered}
P_{i}=\sum_{j=1}^{n} e^{-\alpha\left\|x_{i}-x_{j}\right\|^{2}} \\
\alpha=\frac{4}{r_{a}^{2}}
\end{gathered}
$$

in which $r_{a}$ is a positive constant, and $\|$. $\|$ is Euclidean distance. Thus, the measure of potential for a data point is a function of its distance to all other data points.

A data point with many neighboring data points will have a high potential value [9]. The constant $r_{a}$ is effectively the radius defining a neighborhood; data points outside this radius have little influence on the potential.

After computing the potential of every data point, the data point with the highest potential is selected as the first cluster center $x_{c l}$ with potential value $P_{c l}$. The potential of each data point is then revised by the following formula:

$$
\begin{gathered}
P_{i} \Leftarrow P_{i}-P_{c l} \times e^{-\left.\beta\left\|x_{i}-x_{c}\right\|\right|^{2}} \\
\beta=\frac{4}{r_{b}^{2}}
\end{gathered}
$$

in which $r_{b}$ is a positive constant. Thus, an amount of potential from each data point is subtracted as a function of its distance from the first cluster center. The data points near the first cluster center will have greatly reduced potential, and therefore are unlikely to be selected as the next cluster center. The constant $r_{b}$ is effectively the radius defining the neighborhood that will have measurable reductions in potential. To avoid obtaining closely spaced cluster centers, $r_{b}$ is set to be somewhat greater than $r_{a}$. Chiu [9] suggested $r_{b}=1.5 r_{a}$.

When the potential of all data points have been revised according to (4), the data point with the highest remaining poten- 
tial is selected as the second cluster center $x_{c 2}$ with potential value $P_{c 2}$. After the $k^{\text {th }}$ cluster center has been obtained, the potential of each data point is revised by the formula:

$$
P_{i} \Leftarrow P_{i}-P_{c k} \times e^{-\beta\left\|x_{i}-x_{c k}\right\|^{2}}
$$

in which $x_{c k}$ is the location of the $k^{\text {th }}$ cluster center; and $P_{c k}$ is its potential value.

The process of acquiring new cluster center and revising potentials is repeated until

$$
P_{c k}<\underline{\varepsilon} P_{c 1}
$$

in which $\underline{\varepsilon}$ is a small fraction and is an important factor that will affect the results. If $\varepsilon$ is too small, too many cluster centers will be generated; if $\varepsilon$ is too large, too few data points will be accepted as cluster centers. Chiu [9] suggested $\underline{\varepsilon}=0.15$.

\section{FUZZY-NEURAL SYSTEM}

\section{Establishment of Fuzzy Rule}

Based on subtractive clustering algorithm proposed by Chiu [9], a fuzzy rule base in fuzzy-neural system is established in this study. Fig. 3 shows the flow chart for subtractive clustering. Once all cluster centers are chosen, each cluster center is a fuzzy rule used to describe system behavior. Depending on the membership function, a data point is assigned to a fuzzy rule. Also, membership is defined as adopting the $\alpha$-cut concept, only when the grade of membership for data is larger than the present threshold $\alpha$ do they have the membership of the cluster. Subtractive clustering is used to obtain the cluster center, then the membership function (8) of fuzzy c-means (FCM) clustering analysis and $\alpha$-cut concepts are combined do the data points have the membership of the cluster.

$$
u_{j i}=\frac{1}{\sum_{k=1}^{c}\left(\frac{\left\|x_{i}-x_{c j}\right\|}{\left\|x_{i}-x_{c k}\right\|}\right)^{\frac{2}{m-1}}}
$$

in which $u_{j i}$ is the grade of membership; $x_{i}$ is the $i^{\text {th }}$ input data in input vector $\left\{x_{1}, x_{2}, \ldots . x_{n}\right\} ; m$ is fuzzy index; and $x_{c j}$ is the $j^{\text {th }}$ cluster center. Though a cluster is assigned to a datum point depending on the distance, relationship between data and clusters is not absolute. Its grade of membership is determined by distance. The sum of the membership values for a datum point with respect to all clusters is 1 . Thus, every datum point is not only related to other clusters but also depends on its grade of membership.

FCM is a common method in clustering analysis. However, it is a supervised algorithm, clustering should start with a predefined cluster number. If the cluster number is not predefined, the trial and error method needs to be combined to obtain optimum results through iteration. Otherwise, an unsupervised algorithm is used as a solution.

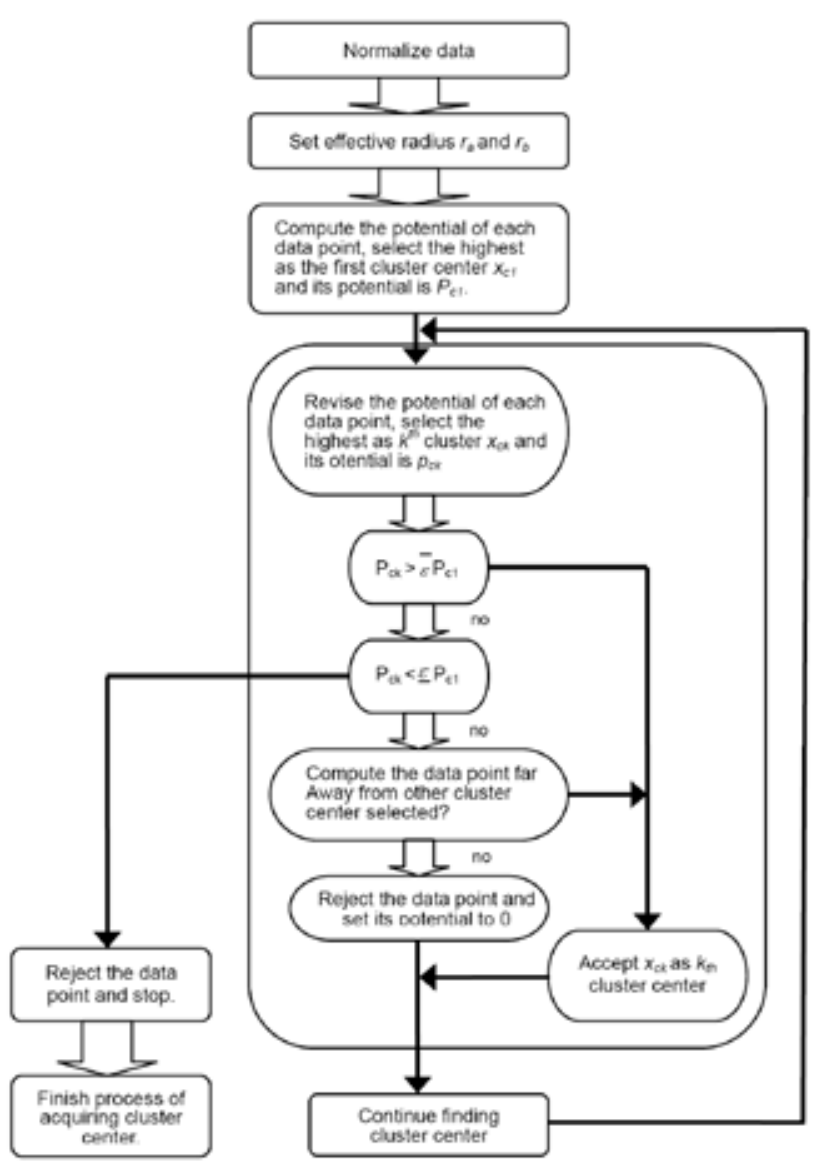

Fig. 3. Flow Diagram for subtractive clustering.

The cluster analysis of a subtractive clustering algorithm is based on the potential value in the feature space. In addition, the location and number of cluster centers is defined by density and the effective radius of space data points. As for automatic system, subtractive clustering is hence more adequate than FCM and more reliable in this study. Moreover, like most nonlinear optimum methods, depending on selection of initial value, i.e., FCM needs to initialize membership matrix, through iteration, the cluster analysis result is judged by the convergence of objection functions. However, like most clustering analysis methods, objection function may converge into the local minimum value instead of the global minimum value.

\section{Neural Network}

An artificial neural network is a computational mechanism able to acquire, represent, and compute a mapping from multivariate space of information to another, given a set of data representing that mapping [22]. It has learning and reminding ability. A variety of networks can be formed with a multiple member of interconnected neurons. Parameters are used as inputs and outputs. Further, the complicated relationship among parameters can be found. The learning and induction process also helps solve complicated problems.

The network used for assessment of liquefaction in this study is the multi-layer perception associated with the back propaga- 


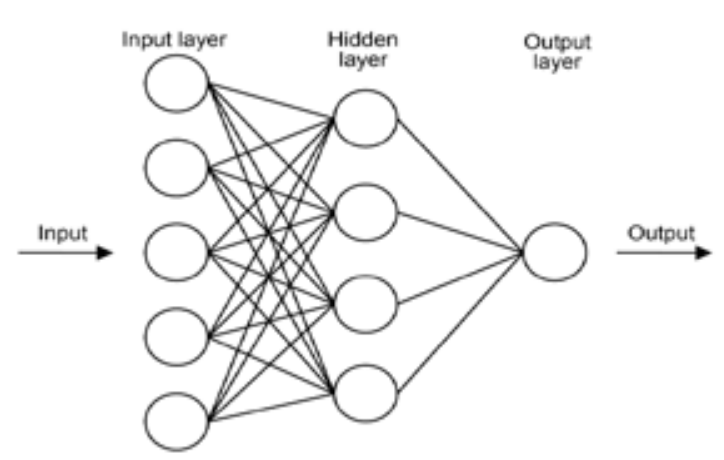

Fig. 4. Illustration of Sub-Network.

tion algorithm, which is a supervised learning algorithm.

To minimize error function during network learning process, the gradient steepest descent method is used to search for optimum solution of error function.

After the determination of its sub-network by membership function, the input vector goes to framework learning. Each sub-network has a hidden layer. The activation function is set to be a nonlinear logic function. The illustration of the sub-network is shown in Fig.4. The output for each sub-network is transformed through the weighted average formula and hyperbolic tangent function into a value between -1 and 1 . When it is larger than 0 , it is within the liquefaction zone. When it is smaller than 0 , it is in the non-liquefaction zone.

Neuron output from the hidden layer in sub-network is:

$$
y_{j}=f_{j}\left(v_{j}(n)\right)=\frac{1}{1+\exp \left(-v_{j}(n)\right)}
$$

in which $y_{j}$ is the neuron output value from a hidden layer in a sub-network; $v_{j}$ is a network net value for a hidden layer; $n$ is a number of learning cycles; and $f_{j}($.$) is a linear activation$ function.

Neuron output from the hidden layer in a sub-network :

$$
y_{k}(n)=f_{k}\left(v_{k}(n)\right)=v_{k}(n)
$$

in which $y_{k}$ is the neuron output value from the hidden layer in the sub-network; $v_{k}$ is the network net value of output layer; $n$ is the number of learning cycles; and $f_{k}($.$) is the linear activation$ function.

The sub-network output value corresponding to each fuzzy rule uses a weighted average formula and the grade of membership as the weighed coefficient for defuzzy as follows:

$$
\hat{v}(n)=\frac{\sum_{p=1}^{c} m_{p} \cdot y_{k p}(n)}{\sum_{p=1}^{c} m_{p}}
$$

in which $\hat{v}$ is sub-network integrated output; $p$ is the $p^{\text {th }}$ fuzzy rule; $c$ is the number of fuzzy rules, i.e. number of fuzzy rules to the sub-network; and $m_{p}$ is the grade of membership for the $p^{\text {th }}$ fuzzy rule.

The final system output is:

$$
\hat{y}(n)=\hat{f}(\hat{v}(n))=\frac{\exp (\hat{v}(n))-\exp (-\hat{v}(n))}{\exp (\hat{v}(n))+\exp (-\hat{v}(n))}
$$

in which $\hat{y}$ is the final system output.

Focusing on learning framework for network parameters, least square method (LSM) and chain rule send back weight error for each layer.

At first, error function is defined as:

$$
E(n)=\frac{1}{2}[y(n)-\hat{y}(n)]^{2}
$$

in which $n$ is number of learning cycles; $y$ is expected output, i.e. actual value; and $\hat{y}$ is the final system output.

The updated sub-network weight is as follows:

$$
\begin{gathered}
\Delta w_{k j}(n)=-\eta \cdot[-(y(n)-\hat{y}(n))] \cdot\left(1-\hat{y}^{2}(n)\right) \\
\cdot \frac{m_{p}}{m_{1}+m_{2}+\cdots+m_{c}} \cdot 1 \cdot y_{j}(n)
\end{gathered}
$$

in which $\eta$ is the learning rate; $n$ is the number of learning cycles; $y$ is the expected output ; $\hat{y}$ is the final system output.; $m_{p}$ is the grade of membership for the $p^{\text {th }}$ fuzzy rule; $y_{j}$ is the neuron output for the sub-network hidden layer; and $c$ is the number of fuzzy rules.

The updated sub-network weight is as follows:

$$
\begin{gathered}
\Delta w_{j i}(n)=-\eta \cdot[-(y(n)-\hat{y}(n))] \cdot\left(1-\hat{y}^{2}(n)\right) \cdot \frac{m_{p}}{m_{1}+m_{2}+\cdots+m_{c}} \\
\cdot 1 \cdot w_{k j}(n) \cdot\left[y_{j}(n) \cdot\left(1-y_{j}(n)\right)\right] \cdot x_{i}(n)
\end{gathered}
$$

in which $x_{i}$ is the input of the sub-network; and $w_{k j}$ is the weight between the network output layer and the hidden layer.

Through $\delta$ rule, bonding correction is defined as follows:

$$
\begin{gathered}
\Delta w_{k j}(n)=\eta \cdot \delta_{k}(n) \cdot y_{j}(n) \\
\Delta w_{j i}(n)=\eta \cdot \delta_{j}(n) \cdot x_{i}(n) \\
\delta_{k}(n)=[y(n)-\hat{y}(n)] \cdot\left(1-\hat{y}^{2}(n)\right) \cdot \frac{m_{p}}{m_{1}+m_{2}+\cdot \cdot+m_{c}} \\
\delta_{j}(n)=\delta_{k}(n) \cdot w_{k j}(n) \cdot\left[y_{j}(n) \cdot\left(1-y_{j}(n)\right)\right]
\end{gathered}
$$

in which $\eta$ is the learning rate; $\delta_{k}$ and $\delta_{j}$ is the area gradient parameter; $y_{j}$ is the output value for the sub-network hidden layer; and $x_{i}$ is the input value for the sub-network.

This study uses the subtractive clustering algorithm to obtain hidden rules among data. Then it uses the IF-THEN rule of fuzzy control to link each rule established after cluster analysis to one artificial neural network. Because the artificial neural sub-network adopts parallel framework, it is possible that several sub-networks are activated at the same time. All activated 
Table 2. The maximum and minimum values of the reference data set.

\begin{tabular}{ccccccc}
\hline & $M$ & $\sigma_{\mathrm{o}}(\mathrm{kPa})$ & $\sigma_{\sigma}^{\prime}(\mathrm{KPa})$ & $q_{d}(\mathrm{MPa})$ & $a_{\operatorname{mad}}(g)$ & $q_{c I N}$ \\
\hline Max. & 7.8 & 364.5 & 227.5 & 25.00 & 0.80 & 300.06 \\
Min. & 5.9 & 16.7 & 16.7 & 0.18 & 0.08 & 2.69 \\
\hline
\end{tabular}

sub-networks undergo learning. Finally, each sub-network output is through defuzzy with weighted average formulas and is transformed into the final output with hyperbolic tangent functions.

\section{DATA SET AND PREPROCESSING}

The case records listed in Table 1 are evaluated using the fuzzy-neural networks. The data base includes 466 CPT-base field liquefaction records from more than 11 major earthquakes between 1964 and 1999 [2, 4-8, 13-20, 25-31]. 21 case records were collected from Japan, 85 from China, 7 from Canada, 219 from the USA, and 134 from Taiwan. 250 of them liquefied and 216 sites did not liquefy. And then, 5 parameters were selected from 466 sites, they are: 1) earthquake magnitude, $M$; 2) total overburden pressure, $\left.\sigma_{0} ; 3\right)$ effective overburden pressure, $\sigma_{0}{ }^{\prime}$; 4) $q_{c}$ value from CPT; and 5) maximum ground acceleration, $a_{\max }$. Moreover, the liquefaction index is also listed in Table 1, it is 1 for liquefaction site and -1 for non-liquefaction site. In Table 2, the maximum and minimum values of each parameter are summarized, where, $q_{c 1 N}$ is defined by $q_{c 1 N}=$ $\left(q_{c} / 100\right) /\left(\sigma_{0}^{\prime} / 100\right)[24]$.

Before using a data set to train the neural network, in order to avoid any inaccuracy and obtain better training results, the data set should be preprocessed. Data is pretreated by using (20). Each parameter is normalized between 0 and 10 .

$$
y=\frac{10 \times x}{x_{\max }-x_{\min }}-\frac{10 \times x_{\min }}{x_{\max }-x_{\min }}=\frac{x-x_{\min }}{x_{\max }-x_{\min }} \times 10
$$

in which $y$ is normalized input parameter; $x$ is the original input parameter; $x_{\max }$ and $x_{\min }$ are the maximum and minimum parameters, respectively.

In this study, system output is between 1 and -1 . When it is larger than 0 , it means within the liquefaction area. When it is smaller than 0, it indicates in non-liquefaction area. After the database is processed through data collection, organization and preprocessing, training is done iteratively until the Root Mean Square Error (RMSE) over all the training patterns are minimized. Training is terminated when RMSE is smaller than the threshold set point 0.1 . Additionally, the calculation will be terminated when RMSE is still equal or larger than 0.1 after 10,000 times of iteration.

\section{DETERMINATION OF NEURONS IN SUB-NETWORK}

It is very important to optimize the number of neurons in the hidden layer. Depending on the complexity of problem, one may increase or decrease the number of neurons. If the number of
Table 3. Results and details of designed fuzzy-neural networks models.

\begin{tabular}{|c|c|c|c|c|c|c|c|c|}
\hline \multirow{2}{*}{ Model } & \multirow{2}{*}{ Input variables } & \multirow{2}{*}{ 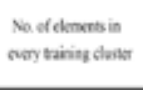 } & \multirow{2}{*}{$\begin{array}{l}\text { No of } \\
\text { malla } \\
\text { scenes }\end{array}$} & \multicolumn{2}{|c|}{ No. ef tiner } & \multicolumn{2}{|c|}{ Enot ute $(\mathrm{S})$} & \multirow{2}{*}{$\begin{array}{l}\text { total mox } \\
\max (\mathrm{N})\end{array}$} \\
\hline & & & & $\ln 2=$ & $\ln x$ & living & Tringy & \\
\hline $\mathrm{CA}$ & $M, a_{0}^{*}, q_{k}, a_{m}$ & $217,116,82,79$ & s & 14 & 6 & 4.0 & 5.17 & 4.29 \\
\hline CAHO & $M, a_{0}^{*}, q_{2}, a_{-2}$ & $217,116,82,79$ & 6 & 14 & 5 & 4.0 & 4.31 & 4.08 \\
\hline $\mathrm{cs}$ & $M, \sigma_{n}, \sigma_{0}^{\prime}, q_{c}, a_{m n}$ & $190,93,114,89$ & 5 & $?$ & 5 & 20 & 4.31 & 2.58 \\
\hline $\operatorname{CsN}$ & $M, \sigma_{1}, \sigma_{0}^{\prime}, \theta_{13}, \theta_{n=}$ & $190,91,113,91$ & 5 & 11 & 5 & 3.14 & 4.31 & 3.43 \\
\hline
\end{tabular}

neurons in hidden layer is less than optimal, the training process cannot reach the global minimum error or the network is not able to learn properly. If the number of neurons in hidden layer is more than optimal, the possibility of over-learning or over-fitting becomes a problem. The back propagation algorithm with a three layer neural network is commonly utilized to analyze the liquefaction occurrence in different sites. Though neural network can have more than one hidden layer, Goh [10], Baziar et al. [3] and Juang et al. [15] found that one hidden layer is good enough for modeling liquefaction problem. The sub-network in this study follows divided-and- conquer methodology for solving liquefaction problem. Therefore, it is not necessary to have too many neurons in hidden layer. After trying different combination of hidden neurons, 5 or 6 neurons are used in the hidden layer of the fuzzy-neural network model.

\section{Effective Radius of Optimized Subtractive Clustering}

The criteria to choose a cluster center for subtractive clustering method is based on potential value of a point and the density of data points nearly. Effective radius $r_{a}$ also plays an important role for the estimation of cluster center. Therefore, effective radius $r_{a}$ determines the number of fuzzy rules in this study, and influences the complexity of model development and the ability of generalization. It should be optimized and an optimum $r_{a}$ that is most suitable for this study is found. $r_{a}$ is a positive constant with value between 0 and $1 . r_{a}$ is determined by changing $r_{a}$ and remaining system parameters kept unchanged, then Root Mean Square Error (RMSE) is checked if it is smaller than a threshold value. 466 data sets are tested to decide $r_{a}$ value, test results are illustrated in Fig. 5. The range of $r_{a}$ value tested is between 0.4 and 0.9. Dashed line in Fig. 5 represents number of fuzzy rules (number of clusters) computed with effective radius $r_{a}$. The smaller the radius value, the more the number clusters. From RMSE curve lines in training and testing phases, it can be seen that when $r_{a}$ is smaller than 0.55 , Even RMSE has much better convergent value (i.e. RMSE has smaller value) during training process, the RMSE in testing phase can not be reduced to a smaller value. (i.e. RMSE value is always larger than minimum value of 0.42 ). That means too many fuzzy rules and sub-networks will be produced, hidden characteristics and classification of database is over-estimated, resulting in too many composite parameters for mapping training data. If $r_{a}$ value is chosen as 0.55 , optimum result can be obtained either in training or testing phase. 


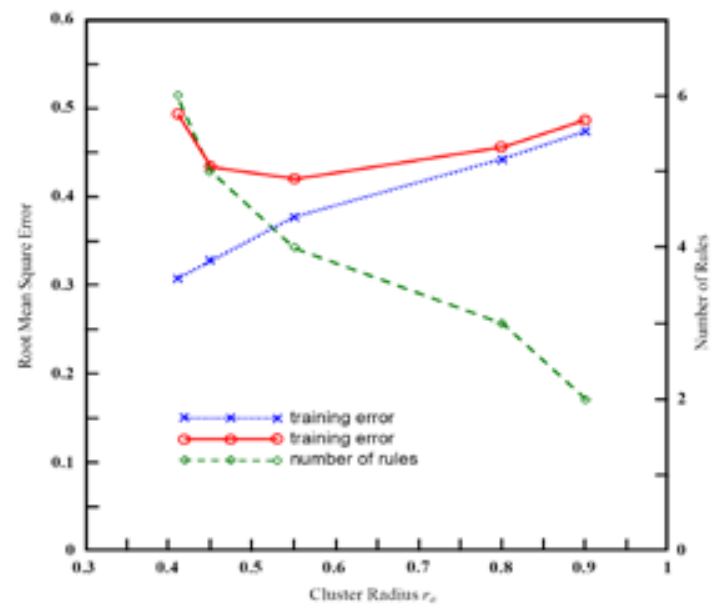

Fig. 5. No. of rules and RMSE vs. different cluster radius $r_{a}$.

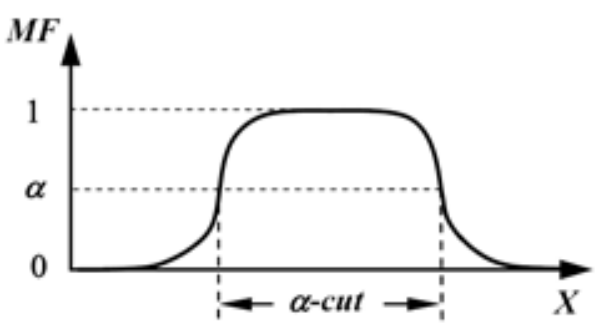

Fig. 6. Illustration of $\alpha$-cut.

\section{Adopted $\alpha$-cut}

It should make sure all data points at least belong to one cluster and no empty cluster exists. Membership is defined as adopting the $\alpha$-cut concept, as shown in Fig.6. Only when the grade of membership for data is larger than the preset threshold $\alpha$ do they have the membership of the cluster. A fuzzy rule will be activated when the grade of membership is larger than $\alpha$. The membership function of FCM (Fuzzy c-means) is used in this study. The sum of the membership values for a datum point with respect to all clusters is 1 . Through optimized effective radius $r_{a}$, 466 data sets are separated into 4 clusters. To make sure all data points at least belong to one sub-network, $\alpha$-cut value is set 0.25 . If there exists any empty cluster, i.e., no any data point belongs to this cluster, rule patching will be processed until better result is met.

\section{ANALYSYS RESULTS}

The 466 collected sets of CPT cases are used for analysis in this study. They are randomly divided into two groups, training group has 350 sets and testing group has 116 sets of data. Depending on different parameter combinations and number of hidden neurons, 4 kinds of neural network models are established. Table 3 shows the results of 4 different models. In model $\mathrm{C} 4$ and $\mathrm{C} 4 \mathrm{H} 6$, the input parameters are earthquake magnitude $M$, effective overburden pressure $\sigma_{0}$, cone resistance $q_{c}$, and maximum ground acceleration $a_{\max }$. Model C4H6 has one more hidden neuron than $\mathrm{C} 4$. Both two models developed by this
Table 4. Relative importance (\%) of input parameters.

\begin{tabular}{ccccccc}
\hline \multirow{2}{*}{ Model } & \multicolumn{6}{c}{ Relative importance(\%) } \\
\cline { 2 - 7 } & $M$ & $a_{\max }$ & $\sigma^{\prime}$ & $\sigma_{0}$ & $q_{c}$ & $q_{c I N}$ \\
\hline C4 & 25.5 & 22.2 & 31.6 & - & 20.7 & - \\
C4H6 & 26.4 & 25.2 & 18.9 & - & 29.5 & - \\
C5 & 17.9 & 24.9 & 17 & 20.7 & 19.5 & - \\
C5N & 18.4 & 24.5 & 17.8 & 20 & - & 19.3 \\
\hline
\end{tabular}

Table 5. Relative importance (\%) of parameters in each cluster of model C5.

\begin{tabular}{cccccc}
\hline \multirow{2}{*}{ Cluster } & \multicolumn{5}{c}{ Relative importance(\%) } \\
\cline { 2 - 6 } & $M$ & $a_{\max }$ & $\sigma^{\prime}{ }_{0}$ & $\sigma_{\theta}$ & $q_{c}$ \\
\hline I & 23.8 & 18.7 & 16.1 & 28.2 & 13.3 \\
II & 17.1 & 26.5 & 22.6 & 7.3 & 26.5 \\
III & 10.0 & 28.8 & 18.8 & 21.5 & 20.9 \\
IV & 16.5 & 31.4 & 10.7 & 17.5 & 23.9 \\
\hline
\end{tabular}

study have $4 \%$ error rate in training phase. Model C4H6 has one less error in testing phase than model C4. However, both models have nearly overall $96 \%$ success rate for judging liquefaction. It shows that very good results can be achieved in this study system with only 5 hidden neurons. Compared with model $\mathrm{C} 4$, models $\mathrm{C} 5$ and $\mathrm{C} 5 \mathrm{~N}$ additionally consider the effect of total overburden pressure $\sigma_{0}$ on liquefaction occurrence. In model $\mathrm{C} 5 \mathrm{~N}$, normalized cone resistance $q_{c l N}$ is considered as input parameter in stead of cone resistance $q_{c}$. From analysis results, model $\mathrm{C} 5$ with only overall error rate $2.58 \%$ has better accuracy than model $\mathrm{C} 5 \mathrm{~N}$ in training phase. Apparently, model $\mathrm{C} 5$ is the best model in this study for liquefaction assessment. Models C5 and $\mathrm{C} 5 \mathrm{~N}$ with additional consideration of $\sigma_{0}$ have better success rate than models $\mathrm{C} 4$ and $\mathrm{C} 4 \mathrm{H} 6$ without consideration of $\sigma_{0}$, shows that $\sigma_{0}$ is an important factor for the assessment of liquefaction. The outputs of training and testing results for model C5 are shown in Figs. 7 and 8. In this study, system output value is between 1 and -1 . When it is larger than 0 , it is within the liquefaction zone. When it is smaller than 0 , it is in non-liquefaction zone. Solid circle points in Figs. 7 and 8 represent the cases with liquefaction, while empty circle points indicate the cases without liquefaction.

Table 4 shows the relative importance for the different models and the different parameter combinations in this study. Model $\mathrm{C} 4$ and $\mathrm{C} 4 \mathrm{H} 6$ have similar relative importance for parameters $M$ and $a_{\max }$, while different for parameters $\sigma_{0}$ ' and $q_{c}$. The trend of parameters' relative importance for model C5 is generally similar to model C5N. In models $\mathrm{C} 5$ and $\mathrm{C} 5 \mathrm{~N}$, the importance of earthquake parameters $\left(M\right.$ and $a_{\max }$ ) is $43 \%$, and $38 \%$ for the in-site stress factors $\left(\sigma_{0}\right.$ ' and $\left.\sigma_{0}\right), 19 \%$ for the cone resistance factor $\left(q_{c}\right.$ or $\left.q_{c 1 N}\right)$. The fuzzy-neural system established in this study follows divide-and-conquer methodology for assessment of liquefaction potential. Table 5 shows the 


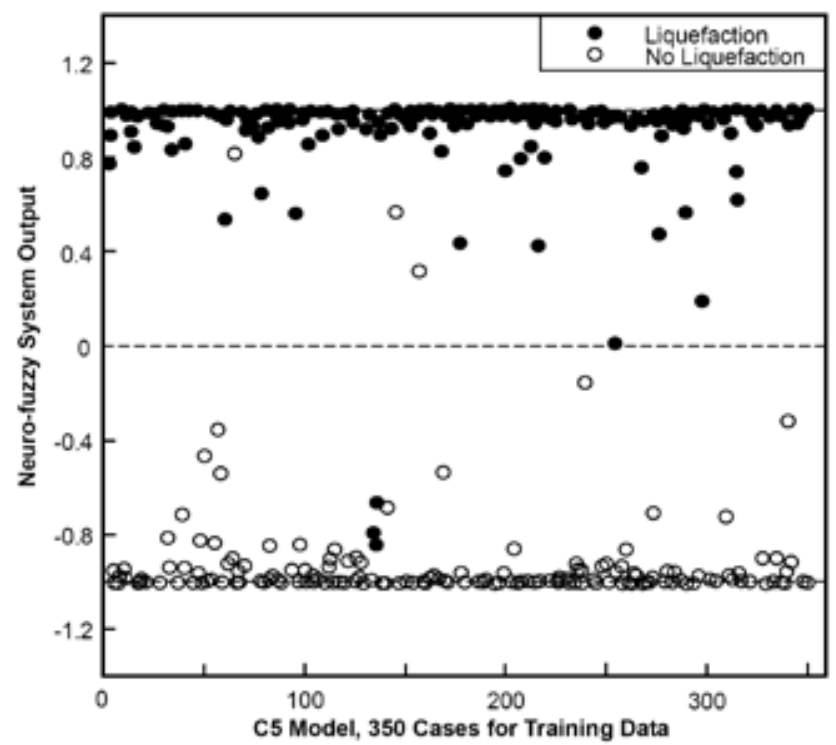

Fig. 7. Results of training phase in model C5.

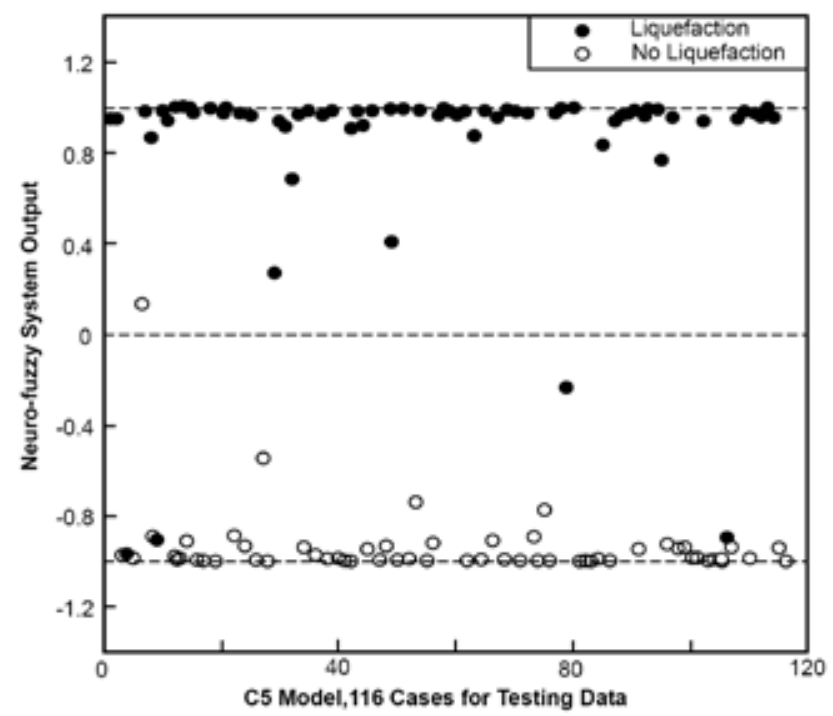

Fig. 8. Results of testing phase in model C5.

relative importance of the four clusters in the C5 model. It can be seen that the main factor for liquefaction assessment in different cluster is different. For example, the liquefaction potential for the $1^{s t}$ cluster is mainly affected by $M$ and $\sigma_{0}$. The $2^{\text {nd }}$ cluster is mainly controlled by $a_{\max }, \sigma_{0}$ ' and $q_{c}$. The $3^{\text {rd }}$ cluster is mainly controlled by $a_{\max }$. The $4^{\text {th }}$ cluster is mainly controlled by $a_{\max }$ and $q_{c}$. Since soil liquefaction induced by earthquake involves great uncertainty and is deeply affected by local geological condition, local stress condition and local earthquake parameters, the model is not limited to use the same neural network for analysis but follows data characteristics for classification and finds hidden rules. It provides a sub-network of learning for similar data clusters and meets the efficiency principle.
Table 1. Summary of testing data.

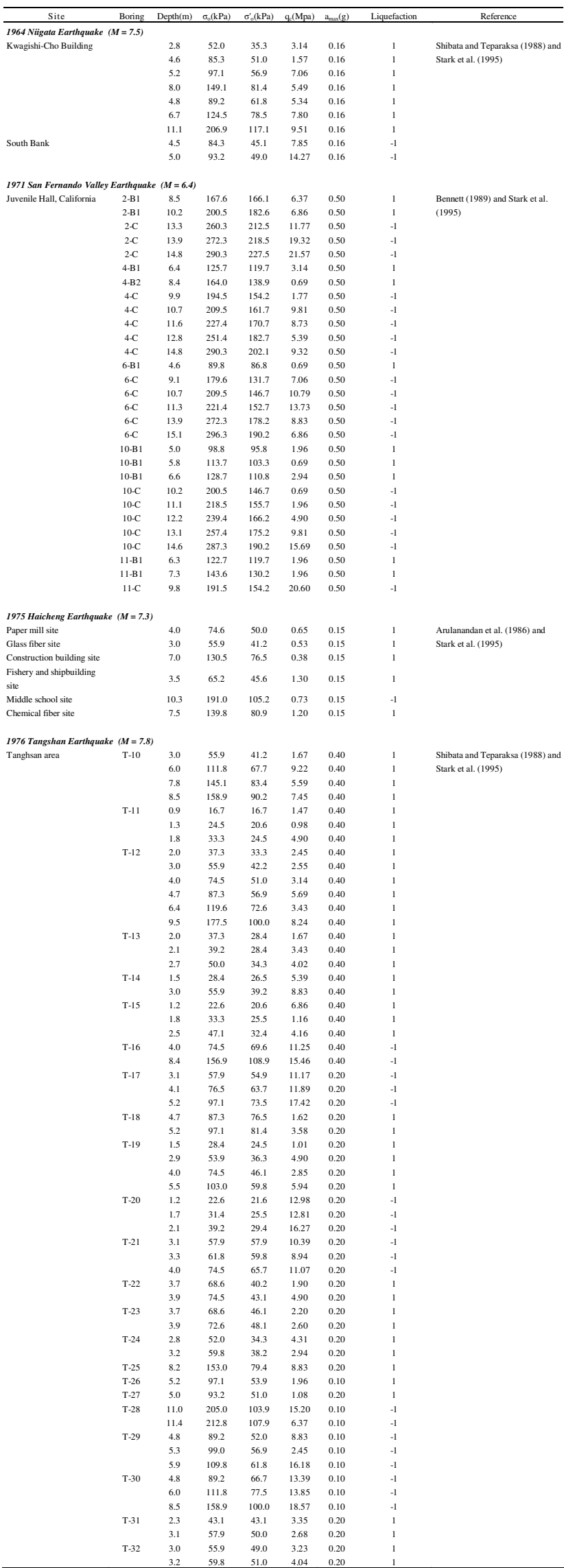




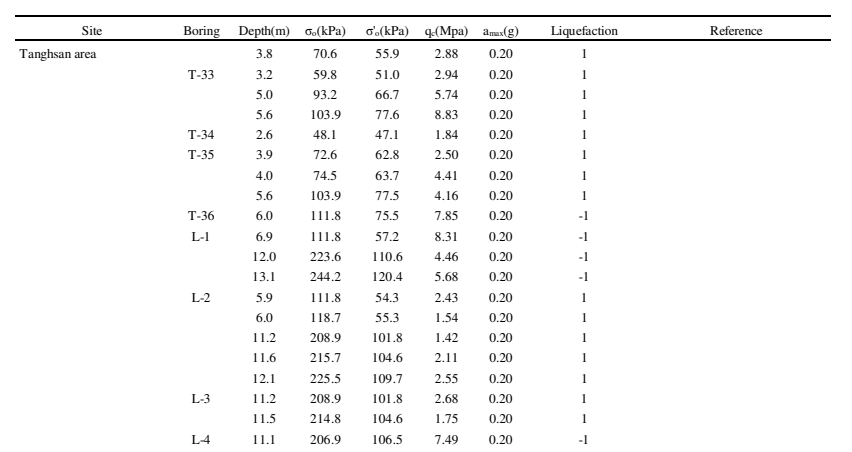

1977 Vrancea Earthquake $(M=7.2)$$$
\text { Dimbovitza (Site 1) }
$$

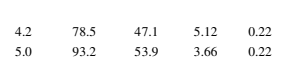
$\begin{array}{lllll}4.2 & 78.5 & 47.1 & 5.12 & 0.22 \\ 5.0 & 93.2 & 53.9 & 3.66 & 0.22 \\ 6.0 & 111.8 & 62.8 & 3.05 & 0.22 \\ 7.0 & 130.4 & 71.6 & 1.29 & 0.22\end{array}$

1979 Imperial Valley earthquake $(M=6.6)$
Heber Road
Unit A2

\begin{tabular}{|c|c|c|c|c|c|}
\hline \multirow[t]{2}{*}{ Heber Road } & Unit A2 & 4.0 & 76.0 & 56.0 & 2.00 \\
\hline & Unit $A 3$ & 4.0 & 76.0 & 56.0 & 4.90 \\
\hline \multirow{11}{*}{$\begin{array}{l}\text { Rver Park } \\
\text { Wildlife }\end{array}$} & Unit C & 5.0 & 95.0 & 45.0 & 6.90 \\
\hline & $1 \mathrm{Cg}$ & 4.8 & 90.3 & 51.8 & 2.90 \\
\hline & $1 \mathrm{Cp}_{\mathrm{p}}$ & 4.8 & 90.3 & 51.8 & 3.90 \\
\hline & $2 \mathrm{Cg}$ & 4.8 & 90.3 & 51.8 & 5.20 \\
\hline & $3 \mathrm{Cg}$ & 4.8 & 90.3 & 51.8 & 5.90 \\
\hline & $3 \mathrm{Cp}$ & 4.8 & 90.3 & 51.8 & 3.80 \\
\hline & $4 \mathrm{Cg}$ & 4.8 & 90.3 & 51.8 & 4.80 \\
\hline & $5 \mathrm{Cg}$ & 4.8 & 90.3 & 59.8 & 4.50 \\
\hline & $6 \mathrm{Cg}$ & 4.8 & 90.3 & 59.8 & 5.10 \\
\hline & $6 \mathrm{Ct}$ & 4.8 & 90.3 & 59.8 & 4.30 \\
\hline & $7 \mathrm{Cg}$ & 4.8 & 90.3 & 59.8 & 5.10 \\
\hline \multirow[t]{5}{*}{ Vail Canal } & $\mathrm{V} 1$ & 4.2 & 78.9 & 63.8 & 10.10 \\
\hline & v2 & 3.9 & 73.2 & 61.1 & 7.20 \\
\hline & v3 & 4.1 & 77.9 & 63.3 & 6.40 \\
\hline & v4 & 4.4 & 82.7 & 65.6 & 5.90 \\
\hline & v5 & 4.7 & 89.3 & 68.7 & 9.00 \\
\hline \multirow{6}{*}{ Kornbloom Road } & $\mathrm{KI}$ & 11.0 & 209.0 & 119.0 & 6.40 \\
\hline & K3 & 11.0 & 209.0 & 119.0 & 6.40 \\
\hline & K4 & 4.0 & 76.0 & 56.0 & 2.30 \\
\hline & K4 & 11.0 & 209.0 & 119.0 & 9.10 \\
\hline & K5 & 4.0 & 76.0 & 56.0 & 1.90 \\
\hline & K5 & 11.0 & 209.0 & 119.0 & 15.50 \\
\hline \multirow[t]{3}{*}{ Radio tower } & $\mathrm{RI}$ & 3.0 & 57.0 & 47.0 & 1.40 \\
\hline & $\mathrm{R} 2$ & 4.5 & 85.5 & 60.5 & 4.20 \\
\hline & R4 & 2.5 & 47.5 & 42.5 & 5.50 \\
\hline \multirow[t]{4}{*}{ McKim Ranch } & M1 & 4.8 & 91.2 & 58.2 & 3.20 \\
\hline & M5 & 6.5 & 123.5 & 73.5 & 5.80 \\
\hline & M7 & 3.2 & 59.9 & 43.4 & 3.30 \\
\hline & M8 & 4.5 & 84.6 & 55.1 & 3.50 \\
\hline
\end{tabular}

$\begin{array}{llllll}\text { 1981 Imperial Valley earthquake }(\boldsymbol{M}=\mathbf{6 . 0}) \\ \text { Wildife } \\ \mathrm{ICg} & 4.8 & 90.3 & 51.8 & 2.90 & 0.33\end{array}$ $\begin{array}{llllll}\mathrm{C} \mathrm{Cg} & 4.8 & 90.3 & 51.8 & 2.90 & 0.33 \\ \mathrm{ICp} & 4.8 & 90.3 & 51.8 & 3.90 & 0.33 \\ 2 \mathrm{Cg} & 4.8 & 90.3 & 51.8 & 5.20 & 0.33 \\ 3 \mathrm{Cg} & 4.8 & 90.3 & 51.8 & 5.90 & 0.33 \\ 3 \mathrm{Cp} & 4.8 & 90.3 & 51.8 & 3.80 & 0.33 \\ 4 \mathrm{Cg} & 4.8 & 90.3 & 51.8 & 4.80 & 0.33 \\ 5 \mathrm{Cg} & 4.8 & 90.3 & 59.8 & 4.50 & 0.33 \\ 6 \mathrm{Cg} & 4.8 & 90.3 & 59.8 & 5.10 & 0.33 \\ 6 \mathrm{Ct} & 4.8 & 90.3 & 59.8 & 4.30 & 0.33 \\ 7 \mathrm{C} & 4 & 903 & 59.8 & 5.10 & 0.33\end{array}$

Vail Canal

Kornbloom Road $\begin{array}{cccccc}\mathrm{K} 4 & 11.0 & 209.0 & 119.0 & 6.40 & 0.37 \\ \mathrm{~K} 4 & 4.0 & 76.0 & 56.0 & 2.30 & 0.37 \\ \mathrm{~K} & 11.0 & 209.0 & 119.0 & 9.10 & 0.37\end{array}$ $\begin{array}{llllll}\mathrm{K} 5 & 11.0 & 209.0 & 119.0 & 15.50 & 0.37\end{array}$ \begin{tabular}{lllllll} 
Radio tower & R1 & 3.0 & 57.0 & 47.0 & 1.40 & 0.29 \\
\hline & R2 & 4.5 & 855 & 605 & 420 & 0.9
\end{tabular} $\begin{array}{lllllll}\text { McKim Ranch } & \text { M1 } & 4.8 & 91.2 & 58.2 & 3.20 & 0.10 \\ & \text { M5 } & 6.5 & 123.5 & 73.5 & 5.80 & 0.10 \\ & \text { M7 } & 3.2 & 59.9 & 43.4 & 3.30 & 0.10\end{array}$ 1983 Nihonkai-Cho Earthquake $(M=7.7)$ $\begin{array}{lllll}1 & 56.9 & 47.1 & 9.81 & 0.23\end{array}$ $\begin{array}{lllll}3.8 & 71.6 & 53.0 & 15.69 & 0.23 \\ 5.0 & 94.1 & 63.7 & 15.08 & 0.23 \\ 2.8 & 530 & 45.1 & 1.76 & 0.3\end{array}$ \begin{tabular}{llll}
45.1 & 1.76 & 0.23 \\
\hline & 510 & 4.02 & 023
\end{tabular} $\begin{array}{lllll}3.4 & 62.8 & 51.0 & 4.02 & 0.23 \\ 5.1 & 94.1 & 65.7 & 7.80 & 0.23\end{array}$

1988 Sangucnay Earthquake ( $M=5.9$ )

1988 Sangucnay Earthqua

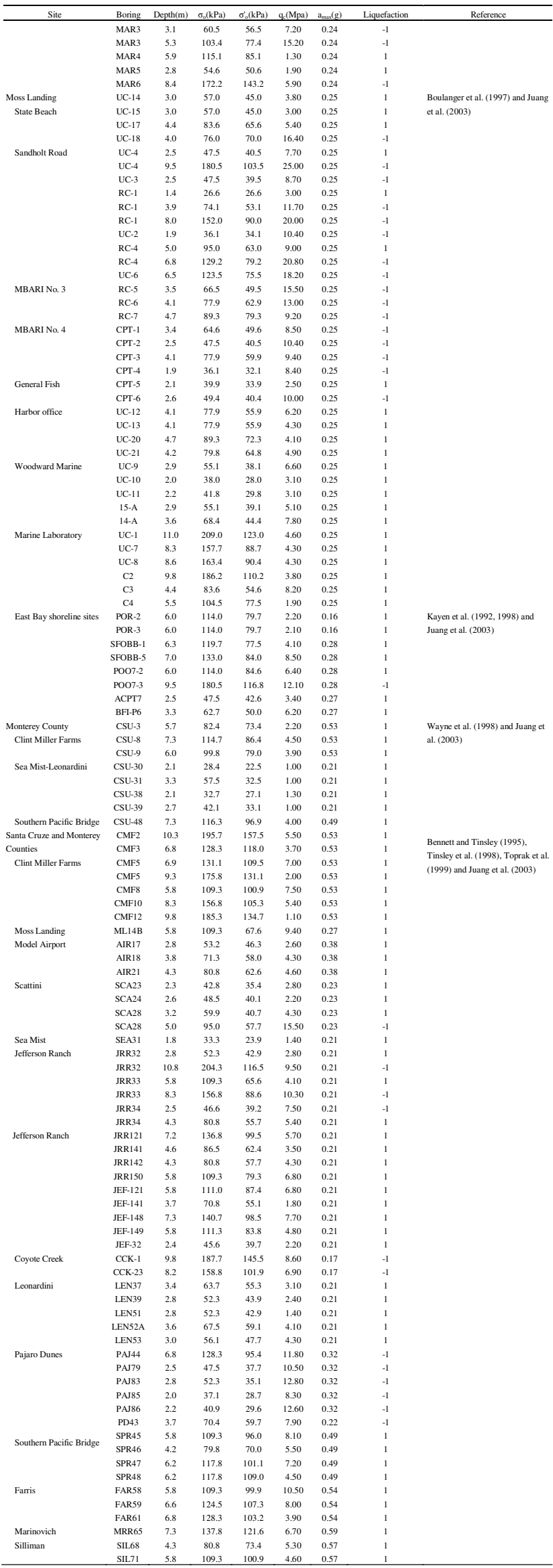




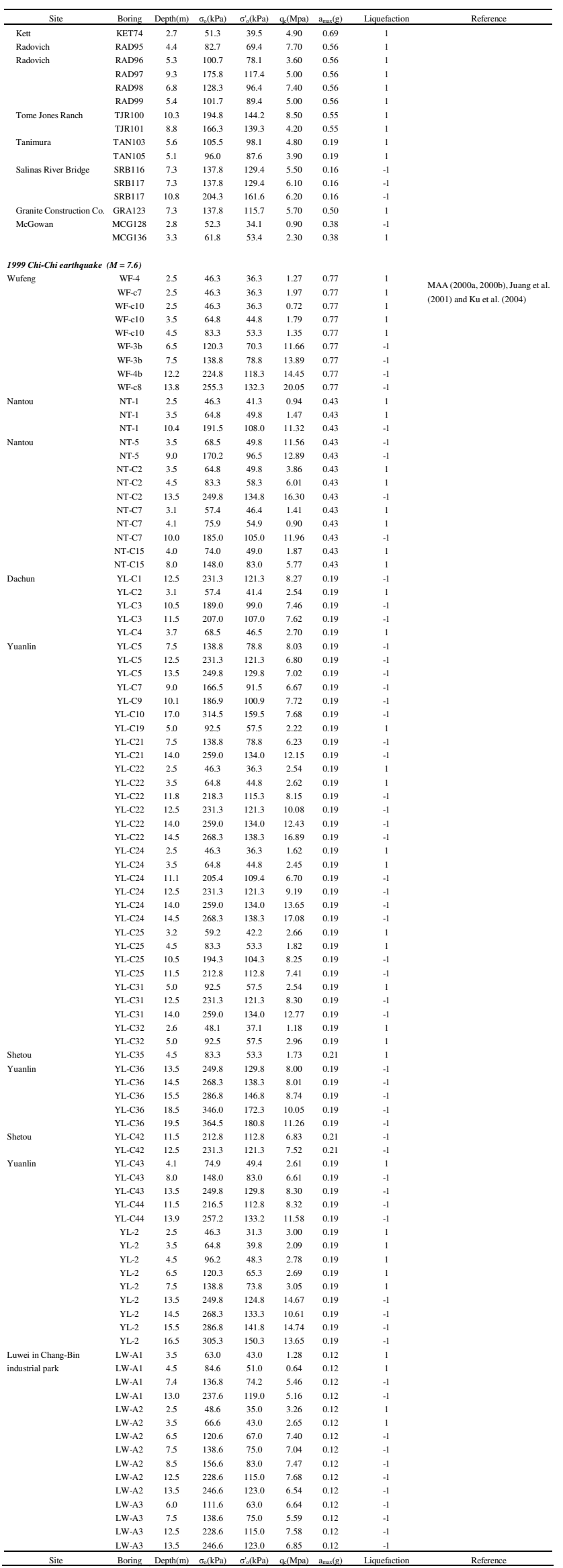

\begin{tabular}{|c|c|c|c|c|c|c|c|}
\hline \multirow{40}{*}{$\begin{array}{l}\text { Luwei in Chang-Bin } \\
\text { industrial park }\end{array}$} & LW-A5 & 6.5 & 124.0 & 70.3 & 6.68 & 0.12 & -1 \\
\hline & LW-A5 & 7.5 & 142.5 & 78.8 & 5.21 & 0.12 & -1 \\
\hline & LW-A5 & 8.5 & 161.0 & 87.3 & 6.12 & 0.12 & -1 \\
\hline & LW-A5 & 9.5 & 179.5 & 95.8 & 7.18 & 0.12 & -1 \\
\hline & LW-A7 & 7.5 & 138.6 & 75.0 & 5.91 & 0.12 & -1 \\
\hline & LW-A7 & 8.5 & 156.6 & 83.0 & 5.38 & 0.12 & -1 \\
\hline & LW-A7 & 9.5 & 174.6 & 91.0 & 6.62 & 0.12 & -1 \\
\hline & LW-A7 & 11.5 & 210.6 & 107.0 & 7.99 & 0.12 & -1 \\
\hline & LW-A7 & 12.5 & 228.6 & 115.0 & 7.38 & 0.12 & -1 \\
\hline & LW-A7 & 13.5 & 246.6 & 123.0 & 7.41 & 0.12 & -1 \\
\hline & LW-A9 & 6.5 & 120.6 & 67.0 & 7.03 & 0.12 & -1 \\
\hline & LW-A9 & 8.5 & 156.6 & 83.0 & 6.73 & 0.12 & -1 \\
\hline & LW-A9 & 10.5 & 192.6 & 99.0 & 6.49 & 0.12 & -1 \\
\hline & LW-A9 & 12.5 & 228.6 & 115.0 & 5.47 & 0.12 & -1 \\
\hline & LW-A9 & 13.5 & 246.6 & 123.0 & 6.32 & 0.12 & -1 \\
\hline & LW-AII & 2.5 & 48.6 & 35.0 & 0.92 & 0.12 & 1 \\
\hline & LW-A10 & 3.5 & 66.6 & 43.0 & 1.50 & 0.12 & 1 \\
\hline & LW-A10 & 4.5 & 84.6 & 51.0 & 0.64 & 0.12 & 1 \\
\hline & LW-A10 & 7.9 & 145.8 & 78.2 & 6.05 & 0.12 & -1 \\
\hline & LW-A10 & 9.5 & 174.6 & 91.0 & 6.76 & 0.12 & -1 \\
\hline & LW-Cl & 3.5 & 68.5 & 44.8 & 2.49 & 0.12 & 1 \\
\hline & LW-Cl & 4.5 & 87.0 & 53.3 & 2.01 & 0.12 & 1 \\
\hline & LW-Cl & 5.5 & 105.5 & 61.8 & 1.89 & 0.12 & 1 \\
\hline & LW-C1 & 6.5 & 124.0 & 70.3 & 1.54 & 0.12 & 1 \\
\hline & LW-Cl & 9.5 & 179.5 & 95.8 & 7.43 & 0.12 & -1 \\
\hline & LW-Cl & 11.6 & 218.3 & 113.6 & 7.72 & 0.12 & -1 \\
\hline & LW-C2 & 5.0 & 93.6 & 55.0 & 6.61 & 0.12 & -1 \\
\hline & LW-C2 & 6.5 & 120.6 & 67.0 & 7.12 & 0.12 & -1 \\
\hline & LW-C2 & 10.5 & 192.6 & 99.0 & 6.08 & 0.12 & -1 \\
\hline & LW-C2 & 12.5 & 228.6 & 115.0 & 7.76 & 0.12 & -1 \\
\hline & LW-C2 & 18.5 & 336.6 & 163.0 & 9.48 & 0.12 & -1 \\
\hline & LW-D1 & 3.5 & 68.5 & 44.8 & 0.20 & 0.12 & 1 \\
\hline & LW-D1 & 5.0 & 96.2 & 57.5 & 5.93 & 0.12 & -1 \\
\hline & LW-DI & 6.5 & $\begin{array}{l}124.0 \\
124.0\end{array}$ & 70.3 & 7.94 & 0.12 & -1 \\
\hline & LW-D1 & 7.5 & 142.5 & 78.8 & 7.57 & 0.12 & -1 \\
\hline & LW-D3 & 2.5 & 50.0 & 36.3 & 0.23 & 0.12 & 1 \\
\hline & LW-D3 & 3.5 & 68.5 & 44.8 & 0.18 & 0.12 & 1 \\
\hline & LW-D3 & 6.1 & 116.6 & 66.9 & 7.24 & 0.12 & -1 \\
\hline & LW-D3 & 8.5 & $\begin{array}{l}161.0 \\
\end{array}$ & 87.3 & 6.21 & 0.12 & -1 \\
\hline & LW-D3 & 125 & 235.0 & 121.3 & 8.83 & 0.12 & \\
\hline
\end{tabular}

\section{CONCLUSION}

Fuzzy-neural network has been used to establish the assessment of liquefaction potential, based on 466 CPT field records collected from the world. This study combines fuzzy theory with subtractive clustering algorithm to constitute a fuzzy-neural system.

Using multiple neural networks, and subtractive clustering analysis to develop a fuzzy-neural network. It has the ability to find the relations between basic parameters and to achieve better results.

In model C5, adding 0 as an input parameter could decrease the total error to $2.58 \%$, and $\sigma_{0}$ also played a more important role than $q_{c}$ in liquefaction assessment.

\section{REFERENCES}

1. Agrawal, G., Chameau, J. L. and Bourdeau, P. L., "Assessing the liquefaction susceptibility at a site based on information from penetrating test," Artificial Neural Networks for Civil Engineers: Fundamentals and Applications. New York: ASSE, pp. 185-214 (1997).

2. Arulanandan, K., Yogachandran, C., Meegoda, N. J., Ying, L. and Zhauji, S., Comparison of the SPT, CPT, SV and electrical methods of evaluating earthquake induced liquefaction susceptibility in Ying Kou city during the Haicheng Earthquake, Proc., Use of In Situ Tests in Geotech. Engng., Geotech. Spec. Publ. No. 6, ASCE, pp. 389-415 (1986).

3. Baziar, M. H. and Nilipour, N., "Evaluation of liquefaction potential using neural-networks and CPT results," Soil Dynamics and Earthquake Engng., Vol. 23, No. 7, pp. 631-636 (2003).

4. Bennett, M. J., McLaughlin, P. V., Sarmiento, J. S. and Youd, T. L., "Geotechnical investigation of liquefaction sites, Imperial Valley, California," Open-File Rep. No. 84-252, U. S. Geological Survey, Menlo Park, California (1984).

5. Bennett, M. J., "Liquefaction analysis of the 1971 ground failure at the San Fernando Valley Juvenile Hall, California," Bull. Assoc. of Engng. Geologists, Vol. 26, No. 2, pp. 209-226 (1989).

6. Bennett, M .J., Tinsley, J. C. III., "Geotechnical data from surface and subsurface samples outside of and within liquefaction-related ground failures caused by the October 17, 1989, Loma Prieta Earthquake, Santa Cruz and Monterey Counties, California," Open-File Rep. No. 95-663, 
US. Geological Survey, Menlo Park, California (1995).

7. Bierschwale, J. G., Stokoe, K. H. II., "Analytical evaluation of liquefaction potential of sands subjected to the 1981 Westmorland Earthquake," Geotechnical Engng. Rep. No. GR-84-15, Univ. of Texas at Austin, Tex. (1984).

8. Boulanger, R. W., Mejia, L. H. and Idriss, I. M., "Liquefaction at Moss Landing during Loma Prieta earthquake," J. Geotech. Geoenviron. Engng., Vol. 123, No. 5, pp. 453-467 (1997).

9. Chiu, S. L., "Fuzzy model identification based on cluster estimation," $J$. Intelligent and Fuzzy System, Vol. 2, pp. 267-278 (1994).

10. Goh, A. T. C., "Neural network modeling of CPT seismic liquefaction data," J. Geotech. Engng., ASCE, Vol. 122, No. 1, pp. 70-73 (1996).

11. Juang, C. H. and Chen, C. J., "CPT-Based liquefaction evaluation using artificial neural networks," Computer-Aided Civil and Infrastructure Engng., Vol. 14, No. 3, pp.221-229 (1999).

12. Juang, C. H., Chen, C. J. and Tien, Y. M., "Appraising cone penetration test based liquefaction resistance evaluation methods: Artificial neural networks approach," Canadian Geotech. J., Vol. 36, No. 3, pp. 443-454 (1999).

13. Juang, C. H. and Chen, C. J., "A rational method for development of limit state for liquefaction evaluation based on shear wave velocity data," Int. J. for Numerical and Analytical Methods in Geomechanics, Vol. 24, pp. $1-27,(2000)$.

14. Juang, C. H., Chen, C. J. and Jiang, T., "Probabilistic framework for liquefaction potential by shear wave velocity," J. Geotech. Geoenviron. Engng., Vol. 127, No. 8, pp.670- 678 (2001).

15. Juang, C. H., Yuan, H. M., Lee, D. H. and Lin, P. S., "Simplified cone penetration test-based method for evaluating liquefaction resistance of soils," J. Geotech. Geoenviron. Engng., Vol. 129, No. 1, pp. 66-80 (2003).

16. Kayen, R. E., Mitchell, J. K., Lodge, A., Seed, R. B., Nishio, S. and Coutinho, R., "Evaluation of SPT-, CPT-, and shear wave-based methods for liquefaction potential assessment using Loma Prieta data," Proc., 4th Japan-U.S. Workshop on Earthquake Resistant Design of Lifeline Facilities and Countermeasures for Soil Liquefaction, M. Hamada and T.D. O'Rouke, eds., State Univ. of New York at Buffalo, N.Y., pp. 177-204 (1992).

17. Kayen, R. E., Mitchell J. K., Seed, R. B. and Nishio, S., "Soil liquefaction in the east bay during the earthquake," The Loma Prieta, California, Earthquake of October 17, 1989: Liquefaction, T.L. Holzer, ed., U.S. Government Printing Office, Washington D.C., pp. B61-B86 (1998).

18. Ku, C. S., Lee, D. H. and Wu, J. H., "Evaluation of soil liquefaction in the Chi-Chi, Taiwan earthquake using CPT," Soil Dynamics and Earthquake Engng., Vol. 24, pp. 659-673 (2004).

19. MMA. Soil Liquefaction Assessment and Remediation Study, Phase I (Yuanlin, Dachun, and Shetou), Summary Report and Appendixes, Taipei, Taiwan: Moh and Associates (MAA) Inc; (2000). [in Chinese].
20. MMA. Soil Liquefaction Investigation in Nantou and Wufeng Areas, Taipei, Taiwan: Moh and Associates (MAA) Inc; (2000). [in Chinese].

21. Olsen, R. S., "Cyclic liquefaction based on the cone penetrometer test," Proceedings of the 1996 NCEER Workshop on Evaluation of Liquefaction Resistance of Soil, NCEER-97-0022, pp. 225-75 (1997).

22. Rahman, M. S., Wang, J., "Fuzzy Neural Network Models for Liquefaction Prediction," Soil Dynamics and Earthquake Engng., Vol. 22, pp. 685- 694 (2002).

23. Robertson, P. K., Campanella, R. G., "Guidelines for use, Interpretation and application of the CPT and CPTU," UBC, Soil Mechanics Series, No.105, Civil Eng. Dept., Vancouver, B.C., V6T 1W5, Canada (1986).

24. Robertson, P. K., and Wride, C. E., "Cyclic liquefaction and its evaluation based on SPT and CPT," Proc., NCEER Workshop on Evaluation of Liquefaction Resistance of Soils, Tech. Rep. No. NCEER-97-0022 (1997).

25. Shibata, T. and Teparaksa, W., "Evaluation of liquefaction potential of soils using cone penetration tests," Soils and Foundations, Vol. 28, No. 2, pp. 49-60 (1988).

26. Stark, T. D. and Olson, S. M., "Liquefaction resistance using CPT and field case histories," J. Geotech. Engng., Vol. 121, No. 12, pp. 856-869 (1995).

27. Tinsley, J. C. III, Egan, J. A. Kayen, R. E., Bennett, M. J., Kropp, A. and Holzer, T. L., "Strong ground and failure, appendix: Maps and descriptions of liquefaction and associated effects," The Loma Prieta, California, Earthquake of October 17, 1989: Liquefaction, T.L. Holzer, ed., U.S. Government Printing Office, Washington, D.C., pp. B287-B314 (1998).

28. Toprak, S., Holzer, T. L., Bennett, M. J. and Tinsley, J. C. III., "CPT- and SPT-based probabilistic assessment of liquefaction," Proc., 7th U.S. Japan Workshop on Earthquake Resistant Design of Lifeline Facilities and Counter measures against Liquefaction, Seattle, Multidisciplinary Center for Earthquake Engineering Research, Buffalo, N.Y., pp. 69-86 (1999).

29. Tuttle, M., Law, K. T., Seeber, L. and Jacob, K., "Liquefaction and ground failure induced by the 1988 Saguenay, Quebec, Earthquake," Canadian Geotech. J., Ottawa, Canada, Vol. 27, No. 5, pp. 580-589 (1990).

30. U.S. Geological Survey (USGS), Effect of Loma Prieta Earthquake on the Marina District, San Francisco, CA. Open-File Rep. No. 90-253, U.S. Geological Survey, Menlo Park, California (1990).

31. Wayne, A. C., Donald, O. D., Jeffrey, P. B. and Hassen, H., "Direct measurement of liquefaction potential in soils of Monterey County, California," The Loma Prieta, California, Earthquake of October 17, 1989: Liquefaction, T. L. Holzer, ed., U.S. Government Printing Office, Washington, D. C., pp. B181- B208 (1998).

32. Yager, R. R. and Filev, D. P., Approximate Clustering via the Mountain Method, Tech. Report \# MII-1305, Machine Intelligence Institute, Iona College, New Rochelle, NY. Also to appear in IEEE Trans. On Systems, Man \& Cybernetics (1992). 